\title{
CC chemokine ligand 1 is released into the airways of atopic asthmatics
}

\author{
R. Montes-Vizuet*, A. Vega-Miranda*, E. Valencia-Maqueda*, M.C. Negrete-García*, \\ J.R. Velásquez ${ }^{\#}$ and L.M. Teran*
}

ABSTRACT: $\quad$ CC chemokine ligand (CCL)1/l-309 is a potent attractant for T-helper cell type 2 lymphocytes. The present study investigates whether this cytokine is released in the bronchoalveolar fluid (BALF) of asthmatic patients.

Measurements of CCL1 using ELISA showed that levels of this cytokine were significantly elevated in BALF from asthmatics compared with normals (median (range) 193 (120-449) $\mathrm{pg} \cdot \mathrm{mL}^{-1}$ versus $\left.30(21-55) \mathrm{pg} \cdot \mathrm{mL}^{-1}\right)$. Differential cell counts in BALF showed that either lymphocyte or eosinophil numbers were elevated in asthmatic compared with normal subjects $\left(10.8 \times 10^{3} \cdot \mathrm{mL}^{-1}\right.$ versus $1.0 \times 10^{3} \cdot \mathrm{mL}^{-1}$ and $1.7 \times 10^{3} \cdot \mathrm{mL}^{-1}$ versus $0.2 \times 10^{3} \cdot \mathrm{mL}^{-1}$, respectively). There was a trend towards a significant correlation between CCL1 levels and lymphocyte numbers in BALF. Separation of BALF using sequential CCL1 affinity column and reverse-phase high-performance liquid chromatography allowed detection of biologically active CCL1. Using immunohistochemistry, CCL1 immunoreactivity was localised predominantly to the airway epithelium.

Interestingly, there was a significant correlation between CC chemokine ligand 1 levels and epithelial cell numbers in bronchoalveolar lavage fluid and between these cells and lymphocyte numbers. Moreover, interleukin-4, interleukin-13 and interferon- $\gamma$ stimulated primary bronchial airway epithelial cells to release $\mathrm{CC}$ chemokine ligand 1 . These findings suggest that CC chemokine ligand 1 may play a role in lymphocyte recruitment in bronchial asthma.

KEYWORDS: Asthma, bronchoalveolar lavage fluid, CC chemokine ligand/I-309, lymphocytes

$\mathrm{t}$ is now widely recognised that asthma is a chronic inflammatory airway disease characterised by infiltration of eosinophils and Tcells. CD4 T-cells that produce T-helper cell (Th) type 2 cytokines, including interleukin (IL)-4, IL-5 and IL-13, play an important role in orchestrating immune and inflammatory processes that lead to immunoglobulin (Ig)E production and allergic inflammation [1]. Activated CD4 T-cells have been a consistent finding in the bronchoalveolar lavage fluid (BALF) and bronchial biopsies of stable asthma $[2,3]$. CD4 lymphocytes have also been shown to increase further following allergen challenge $[4,5]$.

Lymphocyte recruitment from peripheral blood into the airways is regulated by chemokines. The chemokines are a large family of 8-14 kD heparin-binding peptides, which have been subdivided into four subfamilies on the basis of the position of either one or two cysteine residues located near the amino terminus of the protein (CXCL, CC chemokine ligand (CCL), CL and CX3CL) [6, 7]. The cytokine CCL1/I-309 is a member of the CCL chemokine subfamily, which was initially discovered as a gene of unknown function by subtractive hybridisation from the human IL-2-dependent $\gamma \delta$ T-cell line IDP2 [8], but was subsequently shown to be a monocyte and Th2 cell attractant [9-11]. CCL1 is located on human chromosome 17 [12]. Upon activation, CCL1 is produced by a number of cellular sources, including peripheral blood mononuclear cells, monocytes, activated T-lymphocytes and endothelial cells $[8,13,14]$. In vitro studies have shown that CCL1 as well as both CCL22/ monocyte-derived chemokine (MDC) and CCL17/ thymus- and activation-regulated chemokine (TARC) induce migration of lymphocytes, especially of the Th2 phenotype $[13,14]$. CCL22 and CCL17 activate these cells through the CC chemokine receptor (CCR)4, whereas CCL1 uses CCR8 $[15,16]$. It is now well established that CCL22 and CCL17 are released into the airways of asthmatic patients [17-19]. However, the role of CCL1 in asthma remains to be shown. Evidence for the participation of CCL1 in an in vivo role in allergic inflammation derives from an animal study showing that neutralisation of CCL1 with an anti-CCL1 antibody significantly inhibits

\section{AFFILIATIONS}

*Dept of Immunogenetics and Allergy, National Institute of Respiratory Diseases, Mexico City,

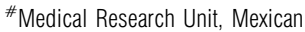
Institute of Social Security, Zacatecas, Mexico.

CORRESPONDENCE L.M. Teran

Dept of Immunogenetics and Allergy National Institute of Respiratory Diseases

Calzada Tlalpan 4502

C.P. 14080

Mexico City

Mexico

Fax: 52556654623

E-mail: Imteran@iner.gob.mx

Received:

November 232004

Accepted after revision:

March 102006

SUPPORT STATEMENT

This work was supported by a grant from the National Institute of Respiratory Diseases Mexico City, Mexico. 
eosinophil recruitment into the lungs of sensitised mice [20]. Another approach has been the use of CCR8 knockout mice. For example, CHENSUE et al. [21] demonstrated that CCR8-/mice had impaired pulmonary eosinophilia. However, CHUNG et al. [22] were unable to show any impairment in both pulmonary Th2 cytokine responses and eosinophilia in CCR8 deficient mice. Although mouse models of asthma have shed light onto the pathogenesis of asthma, they do not necessarily mirror human asthma. In the present study, the authors have investigated CCL1 in the BALF of stable asthmatics.

\section{METHODS \\ Subjects}

A group of 22 symptom-free asthmatics treated with inhaled salbutamol alone and 13 healthy subjects volunteered to participate in the study. The clinical characteristics of both asthmatic and normal subjects are shown in table 1. Their atopic status was confirmed by skin-prick testing with different allergens (i.e. Dermatophagoides pteronnisinus and D. farinae, mixed grass, tree pollen, cat and dog dander and cockroach). The ethics committee of the National Institute of Respiratory Diseases (Mexico City, Mexico) approved the study.

\section{Fibreoptic bronchoscopy}

Bronchoscopy was undertaken according to National Institutes of Health guidelines [23]. Bronchoalveolar lavage (BAL) was performed with saline solution. The recovered BALF was pooled and centrifuged, cells were separated and supernatant was frozen. For differential cell counts, $100 \mu \mathrm{L}$ of cells $\left(4 \times 10^{5}\right.$ cells) were subjected to cytocentrifugation, and were air dried and stained.

\section{High-performance liquid chromatography}

High-performance liquid chromatography (HPLC) was performed at room temperature with an HP1100 liquid chromatography system (Agilent Technologies, Palo Alto, CA, USA) equipped with a quaternary pump and a variable wavelength detector.

\section{Purification of lymphocyte chemotactic activity in BALF}

BALF from five subjects was combined and concentrated using Amicon YM3 filters (Millipore Corporation, Bedford, MA,

\begin{tabular}{|c|c|c|c|c|c|}
\hline & \multicolumn{2}{|c|}{ Sex $n$} & \multirow[t]{2}{*}{ Age yrs } & \multirow[t]{2}{*}{ FEV $1 \%$ pred } & \multirow[t]{2}{*}{$\mathrm{PC}_{20}$} \\
\hline & M & $\mathbf{F}$ & & & \\
\hline Asthmatics & 3 & 19 & $\begin{array}{c}33 \\
(24-49)\end{array}$ & $\begin{array}{c}89.5 \\
(70-120)\end{array}$ & $\begin{array}{c}1.5 \\
(0.8-4.5)\end{array}$ \\
\hline Controls & 7 & 6 & $\begin{array}{c}30 \\
(18-55)\end{array}$ & $\begin{array}{c}104.4 \\
(90-138)\end{array}$ & $32^{\#}$ \\
\hline
\end{tabular}

Data are presented as median (range), unless otherwise stated. M: male; F: female; FEV1: forced expiratory volume in one second; \% pred: \% predicted; PC20: provocative concentration causing a $20 \%$ fall in $\mathrm{FEV}_{1} .{ }^{*}$ : no range can be given as all controls achieved a median of 32 .
USA) before application to a CCL1 affinity column, which had been previously prepared by loading an anti-CCL1 antibody (AF272; R\&D systems, Minneapolis, MN, USA) on a NHydroxysuccinimide-activated sepharose column (HiTrap, $5 \mathrm{~mL}$; Pharmacia, Uppsala, Sweden) [24]. Bound material was eluted from the affinity column and separated by reverse-phase chromatography, as previously described [24, 25]. Fractions obtained from the column were lyophilised before assay for lymphocyte chemotaxis.

\section{Isolation of CD4+ lymphocytes}

Human CD4+ T-cells were purified from healthy donor peripheral blood using Ficoll-Hypaque (Pharmacia Biotech $\mathrm{AB}$, Uppsala, Sweden) density gradient centrifugation, followed by isolation with immunomagnetic beads (CD4+ T-cell isolation kit; Milteny Biotech, CA, USA). Purity was routinely $>95 \%$. For chemotaxis CD4+ cells were stimulated with IL-2 for 5 days. Consistent with a previous report [26] at day 5 of incubation with IL-2, CD4+ cells were found to express the CCL1 receptor CCR8.

\section{Chemotaxis assays}

Chemotaxis of BAL HPLC fractions was performed using a multi-well microchemotaxis chamber, as previously described [27]. Recombinant CCL1 was used as a positive control. Chemotaxis was expressed as a chemotactic index. The antiCCL1 antibody monoclonal antibody (MAB) 272 was used to neutralise experiments.

\section{SDS-PAGE and Western blot}

Sodium dodecyl sulphate-polyacrylamide electrophoresis (SDS-PAGE) was performed using Phast-Gel high-density gel (Pharmacia) according to the manufacturer's protocol. Briefly, electrophoresis was performed at $\mathrm{pH} 6.4$ with Phastgel SDS buffer strips (Healthcare Biosciences, Uppsala, Sweden) that contained $0.112 \mathrm{M}$ Tris $/ 0.112 \mathrm{M}$ acetate buffer, and was visualised by use of a silver staining kit (Sigma, St Louis, MO, USA). Western blot analysis was performed to detect CCL1 using a specific polyclonal antibody (anti-human CCL1 antibody; Peprotech Inc., Rockhill, NJ, USA).

\section{Immunohistochemistry}

Bronchial biopsies were fixed in paraformaldehyde and were paraffin embedded. Immunohistochemistry for CCL1 was performed by indirect immunoperoxidase staining, as previously described [28]. The sections were counterstained using Mayer's haematoxylin (Vector Laboratories Inc., Burlingame, CA, USA).

\section{RNA preparation and analysis}

Total RNA was isolated from BAL cells using the TRIzol method. Total cellular RNA was quantified and reverse transcribed for CCL1, CCR8, reduced glyceraldehyde phosphate dehydrogenase and $\beta_{2}$ microglobulin PCR reaction, as previously described [29]. Specific primers had the following sequences: CCL1 (Forward 5'-GTTGCTTCTCATTTGCGG-3'; Reverse 5'-GTAGGGCTGGTAGTTTCGG-3)'; CCR8 (Forward 5'-CATCACCCTCATGAGTGTGG-3'; Reverse 5' - CACGTTGAATGGGACCCAGA-3'); $\beta_{2}$ microglobulin (Forward 5'-GCTTACATGTCTCGATCCGACTTAA-3'; Reverse 5'-CTCGCGCTACTCTCTCTTTCTGG-3'). 


\section{Culture and stimulation of human airway epithelial cells}

Human bronchial airway epithelial cells (BAEC) were isolated from bronchial epithelia mucosa tissue and grown as previously described [24]. Subsequently, cells were incubated with IL-4, IL-13 and interferon (IFN)- $\gamma$ at concentrations of $10 \mathrm{ng} \cdot \mathrm{mL}^{-1}$ for $24 \mathrm{~h}$. The purity and identity of the cells were checked by immunohistochemistry using the anti-citokeratin MAB AE1/AE3 (Zymed, San Francisco, CA, USA).

\section{Measurement of CCL1}

Measurement of immunoreactive CCL1 in both $2 \times$ concentrated BALF and airway epithelial culture supernatant was performed using a two-AB sandwich ELISA kit (R\&D Systems) following the manufacturer's protocol. The primary anti-CCL1 capture antibody was the MAB 272; the secondary antibody was a biotinylated anti-CCL1 antibody CCL1 (R\&D Systems). A list of the antibodies used in the different experiments is shown in table 2. A standard curve consisting of serial dilutions from $0.007-1 \mathrm{ng} \cdot \mathrm{mL}^{-1}$ of recombinant human CCL1 (R\&D Systems) was included in the assay. Concentration of CCL1 in samples was calculated from the standard curve, and, in the case of BALF, concentrations of this cytokine were corrected for the initial two-fold concentration. The lower limit of detection was $7 \mathrm{pg} \cdot \mathrm{mL}^{-1}$ and the inter-assay coefficient variation was $5 \%$.

\section{Statistical analysis}

Analysis of CCL1 in BALF and BAL cell counts was performed using the Mann-Whitney U-test for unpaired data. Correlations between CCL1 and infiltrating cells in BALF were evaluated using Spearman's nonparametric rank correlation coefficient test. A value of $\mathrm{p}<0.05$ was considered statistically significant.

\section{RESULTS}

\section{Clinical findings}

The median age for asthmatics and controls was 30 and 33 yrs, respectively. Lung function data showed that asthmatics suffered from mild-to-moderate asthma. The forced expiratory volume in one second (FEV1; median) \% predicted in asthmatics and normals was $89.5 \%$ (range $70-120 \%$ ) and $104.4 \%(90-138 \%)$, respectively. All asthmatic patients were atopic; control subjects were nonatopic. Clinical data are shown in table 3. No complications were seen in any of the patients following bronchoscopy. Minor complaints, such as sore throat and mild cough, were seen in three patients.

\begin{tabular}{lcc} 
TABLE 3 & $\begin{array}{l}\text { Differential and total cell counts in } \\
\text { bronchoalveolar lavage fluid }\left(\times 10^{3} \cdot \mathrm{mL}^{-1}\right)\end{array}$ \\
& Asthmatics & Normals \\
& & \\
& $21.8(17-60)$ & $32.6(1.8-129)$ \\
Macrophages & $10.8(0-84)^{\#}$ & $1(0-3.4)$ \\
Lymphocytes & $5.8(0-15)$ & $2.1(0-10.8)$ \\
Neutrophils & $1.7(0-8)^{*}$ & $0.24(0-0.8)$ \\
Eosinophils & $1.3(0-9.6 .2)^{*}$ & $0.02(0-0.35)$ \\
Epithelial cells & $38(3-100)$ & $42.1(1.9-140)$ \\
Total cell count & & \\
\hline &
\end{tabular}

\section{BALF and cell population}

BAL was obtained from all 35 subjects taking part in the study. There was no significant difference in the volume of fluid recovered from asthmatic and normal subjects $(75 \pm 10 \mathrm{~mL}$ versus $62 \pm 12 \mathrm{~mL} ; \mathrm{p}<0.05)$.

Differential cell counts in BAL showed that lymphocytes, eosinophils and epithelial cells numbers were significantly elevated in asthmatics compared with normals $\left(10.8 \times 10^{3} \cdot \mathrm{mL}^{-1}\right.$ versus $1.0 \times 10^{3} \cdot \mathrm{mL}^{-1}(\mathrm{p}<0.005), 1.7 \times 10^{3} \cdot \mathrm{mL}^{-1}$ versus $0.24 \times 10^{3} \cdot \mathrm{mL}^{-1}$ $(\mathrm{p}<0.01)$ and $1.3 \times 10^{3} \cdot \mathrm{mL}^{-1}$ versus $0.02 \times 10^{3} \cdot \mathrm{mL}^{-1} \quad(\mathrm{p}<0.05)$, respectively; table 3 ). There was no difference in the number of macrophages and total cell counts in asthmatic and normal subjects.

\section{Measurements of CCL1 in BALF}

Measurements of CCL1 with ELISA showed that levels of this cytokine were significantly elevated in BALF from asthmatics compared with normals (median (range) 193 (108-449) $\mathrm{pg} \cdot \mathrm{mL}^{-1}$ versus 30 (15-55) $\mathrm{pg} \cdot \mathrm{mL}^{-1}, \mathrm{p}<0.001$; fig. $\left.1 \mathrm{a}\right)$.

There was a trend towards a correlation between CCL1 levels and lymphocyte numbers in BALF, although this just failed to reach statistical significance $(r=0.4, p=0.08$; fig. 2a). Interestingly, there was a significant correlation between CCL1 levels and epithelial cells $(r=0.73, p=0.001$; fig. $2 b)$ and between these cells and lymphocytes $(r=0.6, p=0.02$; fig. $2 c)$. However no significant correlation was seen between CCL1 and any other infiltrating leukocytes, including macrophages and eosinophils. In addition, a significant correlation between concentrations of CCL1 and bronchial hyperreactivity (provocation concentration of methacholine causing a $20 \%$ fall in FEV1 (PC20)) was not seen.

TABLE 2 Antibodies used in experiments

\begin{tabular}{|c|c|c|c|c|c|}
\hline MAB 272 & R\&D Systems, Minneapolis, MN, USA & Anti-CCL1 human monoclonal & Mouse & $\lg G 1$ & ELISA \\
\hline BAF22 & R\&D Systems, Minneapolis, MN, USA & Anti-CCL1 human biotinylated & Goat & $\lg G$ & ELISA \\
\hline AF272 & R\&D Systems, Minneapolis, MN, USA & Anti CCL1 human polyclonal & Goat & $\lg G$ & Inmunohistochemistry \\
\hline $500-P 110$ & Peprotech Inc., Rockhill, NJ, USA & Anti-human I-309 biotinylated & Rabbit & $\lg G$ & $\begin{array}{l}\text { Western blot } \\
\text { immunohistochemistry }\end{array}$ \\
\hline
\end{tabular}

Ig: immunoglobulin; MAB: monoclonal antibody; BAF: biotinylated antibody; AF: polyclonal antibody; CCL: CC chemokine ligand. 

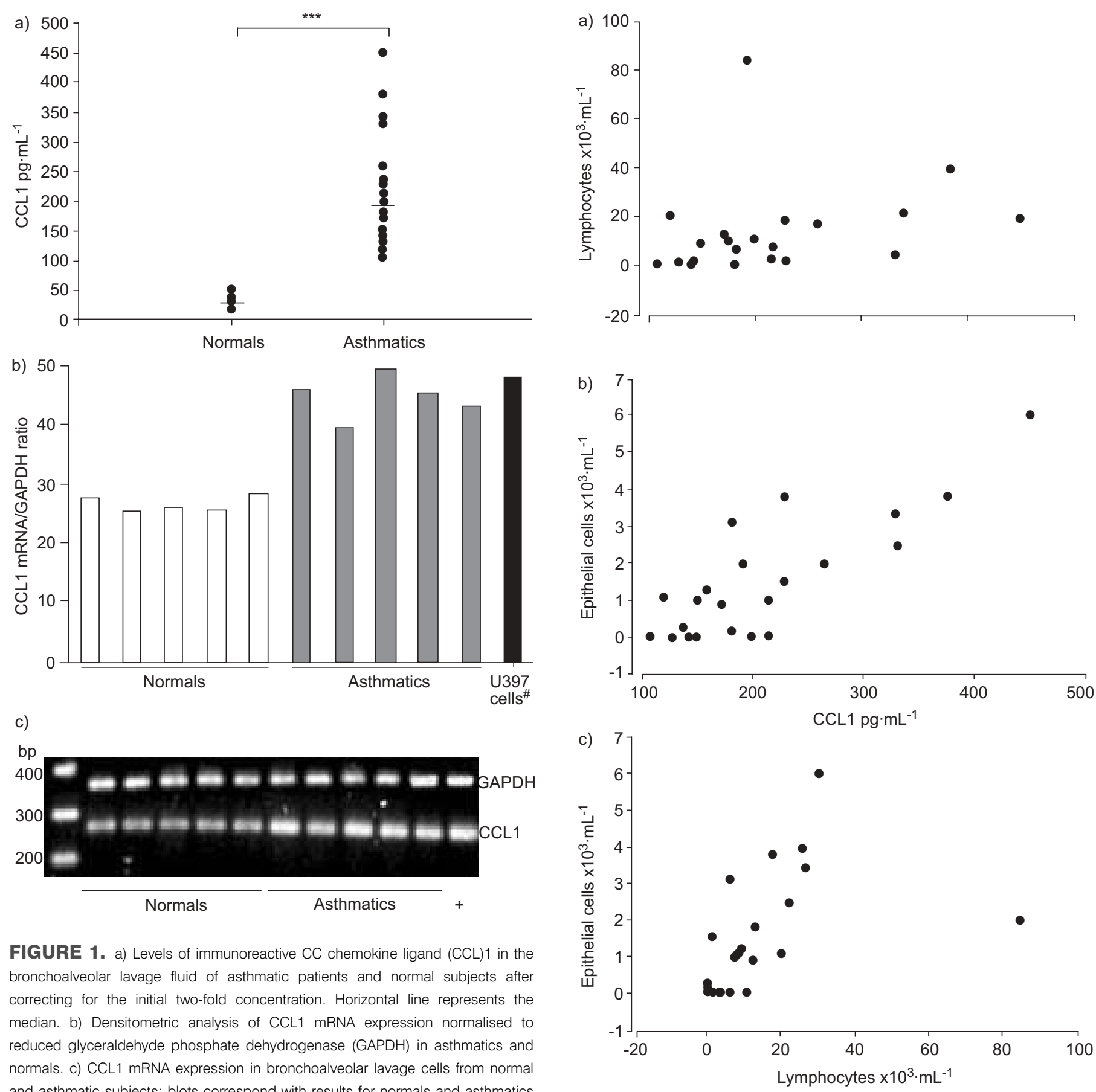

FIGURE 1. a) Levels of immunoreactive CC chemokine ligand (CCL) 1 in the bronchoalveolar lavage fluid of asthmatic patients and normal subjects after correcting for the initial two-fold concentration. Horizontal line represents the median. b) Densitometric analysis of CCL1 mRNA expression normalised to reduced glyceraldehyde phosphate dehydrogenase (GAPDH) in asthmatics and normals. c) CCL1 mRNA expression in bronchoalveolar lavage cells from normal and asthmatic subjects; blots correspond with results for normals and asthmatics given in b). ${ }^{\#}$ : CCL1 gene expression in PMA-stimulated U937 cells as a positive control (+). ${ }^{* * *}: p<0.001$

Using SDS-PAGE and Western blot CCLI was detected in BALF derived from asthmatics but not control subjects (fig. 3).

\section{CCL1 MRNA in BAL cells}

CCL1 mRNA was investigated in BAL cells derived from normal and asthmatic subjects. Constitutive CCL1 mRNA was observed in BAL cells from normal subjects. However, increased CCL1 mRNA expression was seen in BAL cells derived from asthmatic compared with normal subjects (fig. 1b). 
$14.4 \mathrm{kD}$

$10.7 \mathrm{kD}$

$8.15 \mathrm{kD}$

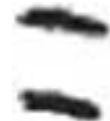

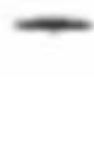

3

further investigate this cytokine, nasal polyps were also analysed using immunohistochemistry. Interestingly, CCL1 immunoreactivity was also localised to the airway epithelium of nasal polyps (fig. 6d).

\section{Bronchial airway epithelial cells release CCL1 in vitro}

Having demonstrated CCL1 immunoreactivity localised to the bronchial airway epithelium, the present authors next investigated whether primary BAEC release this chemokine upon stimulation with either Th1 (IFN- $\gamma$ ) or Th2 cytokines (IL-4 and -13). Measurements of CCL1 in the culture supernatant showed that these cells produced low levels of CCL1 constitutively. Among the cytokines, IL-4 was the strongest stimulus for the release of CCL1, followed by IL-13 and IFN- $\gamma$ (fig. 7).

\section{DISCUSSION}

A novel finding of the present study is the demonstration that CCL1 is released in high concentrations into the airway epithelial lining fluid of asthmatic patients. Interestingly, BAL CCL1 was found to activate CD4 cells as assessed in chemotactic assays. With immunohistochemistry, CCL1 was

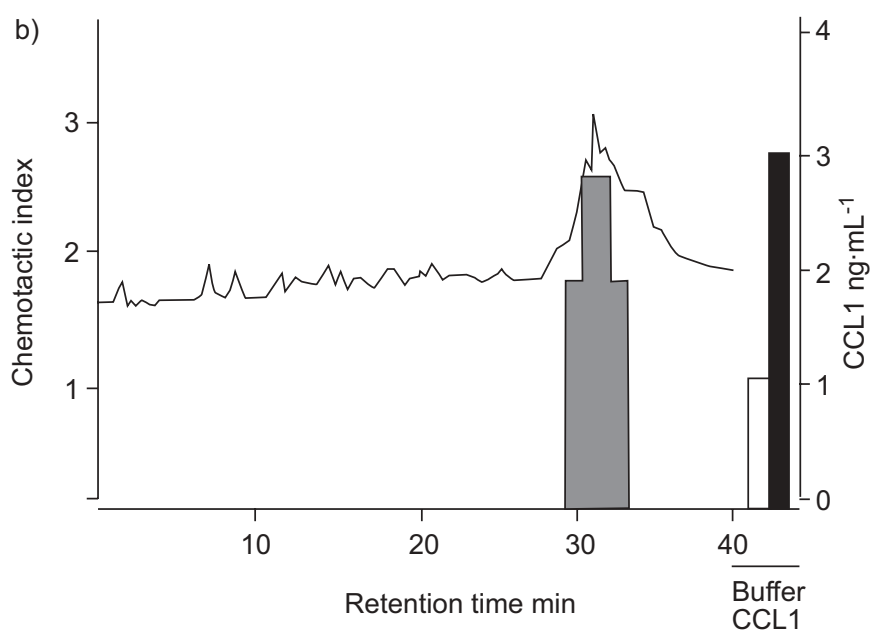

FIGURE 4. Lymphocyte chemotactic activity (LCA) from bronchoalveolar lavage fluid after sequential CC chemokine ligand (CCL)1/I-309 affinity chromatography and reverse-phase chromatography resolved into a peak of LCA ( $\square)$. CD4 chemotaxis in response to individual fractions is given as a chemotactic index. Negative control (buffer; $\square$ ) per definition gave a chemotactic index of 1 . Recombinant CCL1 (घ) was used as a positive control. -----: acetonitrile gradient; —: CCL1 ELISA measurement.

using different pooled BALF samples. Incubation of BAL CCL1 with a neutralising anti-CCL1 antibody (MAB 272) blocked the BAL-LCA (fig. 5b). For chemotaxis assays CCR8 was induced in CD4 lymphocytes by incubating these cells with IL-2 for 5 days (fig. 5a).

\section{CCL1 immunoreactivity in bronchial biopsies}

To investigate potential cellular sources of CCL1, the technique of immunohistochemistry was applied to bronchial biopsies. CCL1 immunoreactivity was localised predominantly to the airway epithelium (fig. $6 \mathrm{a}$ and c). Similar findings were observed in biopsies derived from four different asthmatics. In contrast, CCL1 immunoreactivity was not seen in bronchial biopsies derived from normal subjects (data not shown). To
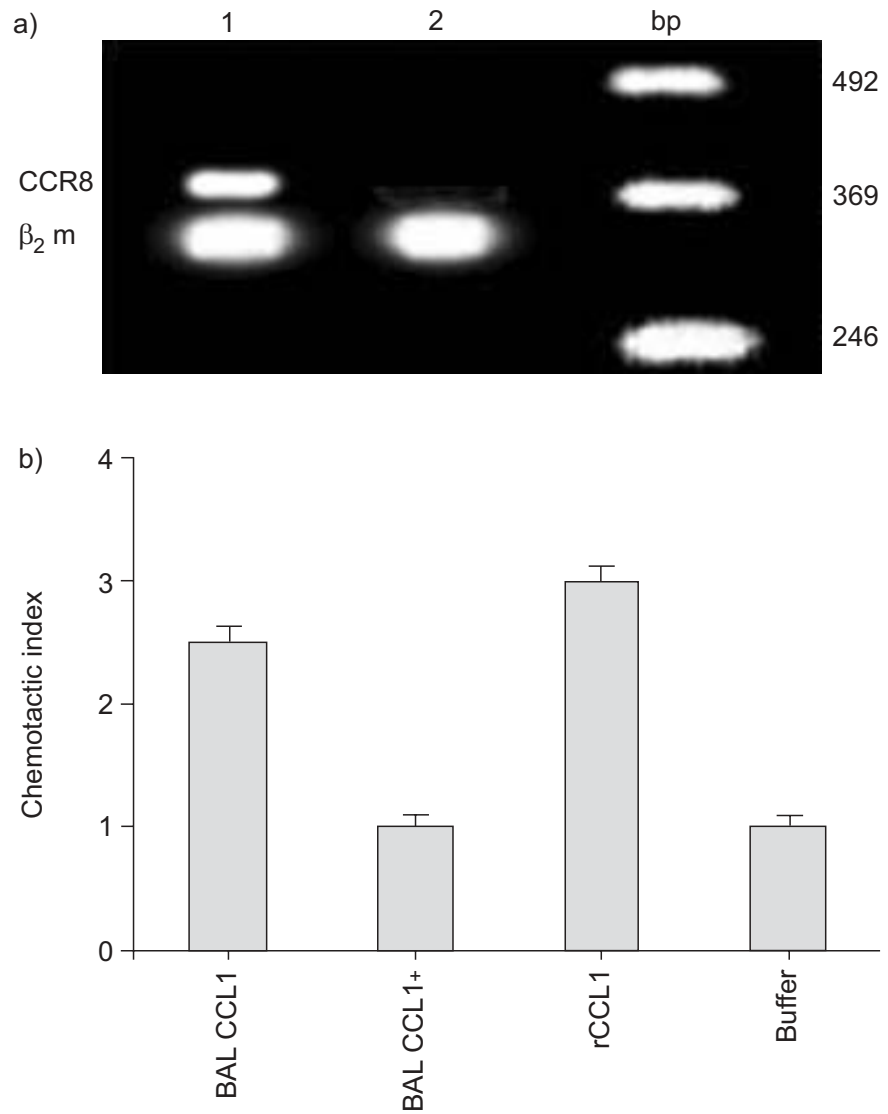

FIGURE 5. a) Interleukin-2-stimulated CD4+ cells express CC chemokine receptor 8 (CCR8; lane 1). Nonstimulated lymphocytes do not express this receptor (lane 2). b) Neutralisation of lymphocyte chemotactic activity (LCA) of bronchoalveolar lavage (BAL) $C C$ chemokine ligand $(C C L) 1$ (mean of three separate experiments). BAL CCL1 (5 ng. $\mathrm{mL}^{-1}$ ) was incubated with $1 \mu \mathrm{g}$ of the monoclonal antibody 272 (neutralising AB to CCL1) for 15 min before the chemotactic assay. Chemotactic activity is shown as a chemotactic index. Recombinant (r)CCL1 $\left(10^{-8} \mathrm{M}\right)$ was used as a positive control. Negative control (buffer) per definition, gave a chemotactic index of 1 . bp: base pair; $\beta_{2} \mathrm{~m}$ : $\beta_{2}$ macroglobulin. 

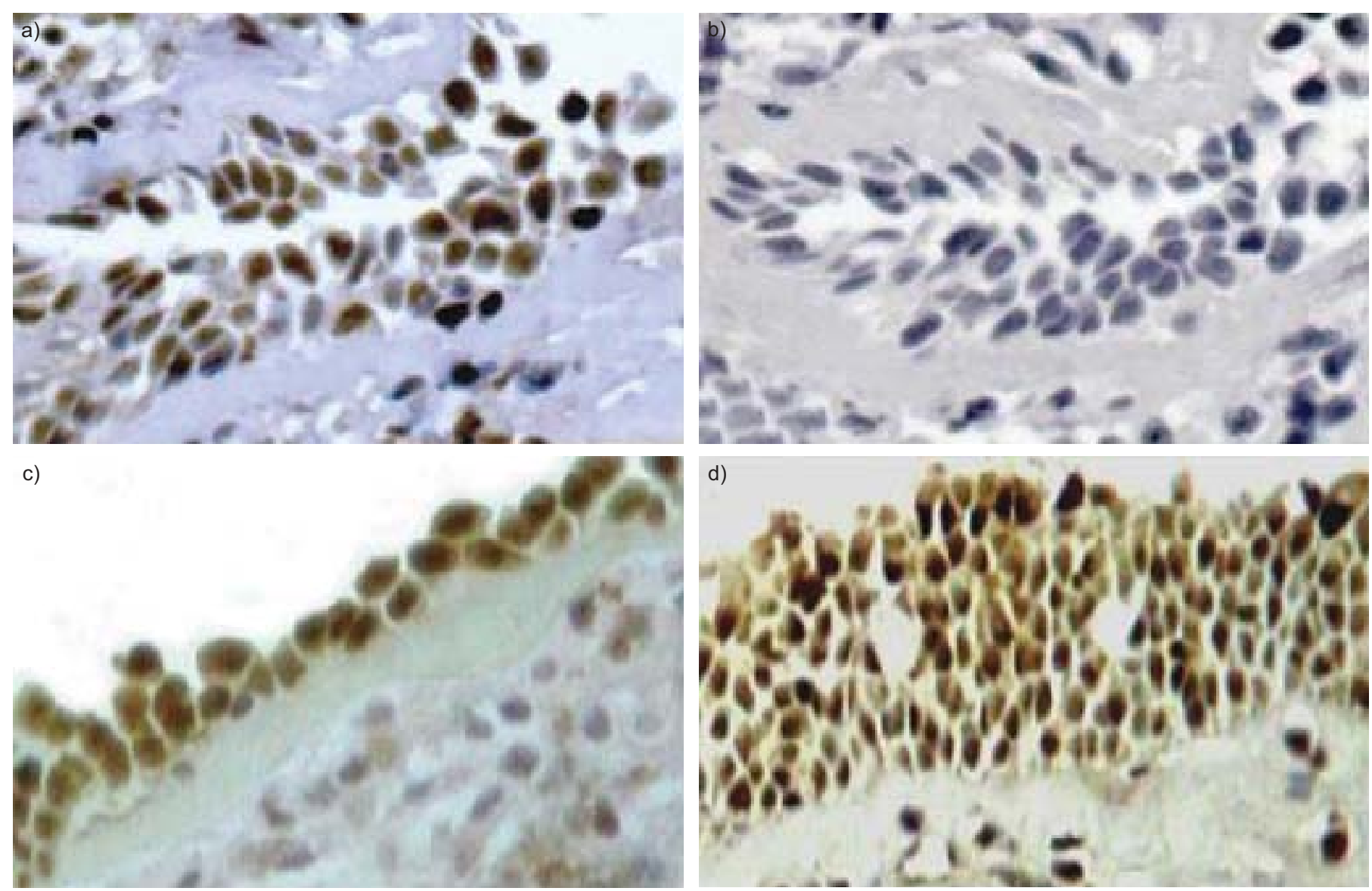

FIGURE 6. a and c) Localisation of immunoreactive CC chemokine ligand (CCL) 1 to the airway epithelium of bronchial biopsies derived from two asthmatics. b) Negative control of a bronchial biopsy (instead of the anti-CCL1/I-309 antibody the isotype control antibody goat immunoglobulin G 15256 was used). d) Immunoreactive CCL1 to the airway epithelium of a nasal polyp. See Methods section for further information on immunohistochemistry.

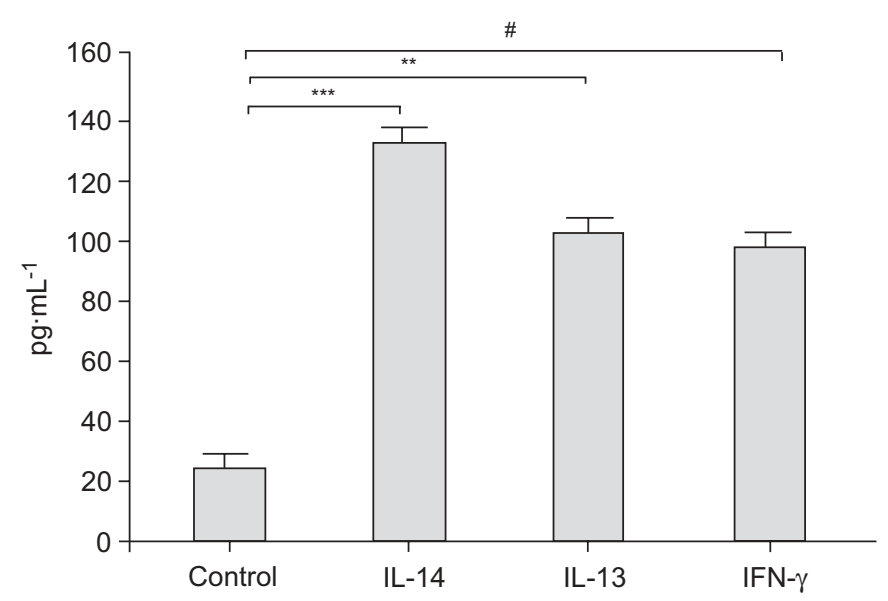

FIGURE 7. Levels of immunoreactive CC chemokine ligand 1 in the culture supernatants $(n=4)$ derived from both the cytokine-stimulated primary bronchial airway epithelial cells (BAEC) as well as nonstimulated BAEC supernatants (control). Error bars represent median values. IL: interleukin; IFN: interferon. *: $p<0.02 ; * *: p<0.01 ; * * *: p<0.001$ localised predominantly to the bronchial airway epithelium. Human bronchial epithelial cells were found to release high concentrations of CCL1 upon cytokine stimulation in vitro.

CCL1 was originally characterised as a chemotatic factor for monocytes, and subsequently shown to be a potent Th2 lymphocyte attractant [9-11]. As Th2 lymphocytes play an important role in asthma, this cytokine has attracted major attention in allergic inflammation. The murine homologue of CCL1/I-309 is CCL1/T-cell activation-3 [30, 31]. CCL1/T-cell activation-3 has been implicated in several models of inflammatory diseases, including inflammatory bowel disease, experimental allergic encephalomyelitis and allergic asthma $[20,32,33]$. To date, however, the role of this cytokine in asthma remains to be shown.

This is the first study to demonstrate that CCL1 is released into the airways of asthmatic patients. Indeed, levels of this cytokine were six-fold greater in asthmatics compared with normals. A previous group failed to detect CCL1 in BALF from asthmatics exposed to allergen challenge, but detected other chemokines such as CCL17 (TARC), CCL22 (MDC) and CXCL10 (interferon-inducible protein-10) [18]. Their failure to detect CCL1 could be explained by the fact that CCL1 was investigated in neat BALF. It's also possible that the antibodies used in their ELISA were not sensitive enough to detect CCL1. 
In the present study, BALF was concentrated 2-10 times and it was demonstrated that $2 \times$ concentrated BALF was good enough to detect CCL1. The presence of CCL1 in BALF was further confirmed by Western blot. It is well established that BALF is a dilution of airway epithelial lining fluid of 1:100 to 1:200 [34-37]. A finding of $193 \mathrm{pg} \cdot \mathrm{mL}^{-1}$ thus reflects a concentration of $3.8-38 \mathrm{ng} \cdot \mathrm{mL}^{-1}$ in airway lining fluid. Expressing cytokines levels per $\mathrm{mL}$ of BALF after correction for the initial concentration is a well-established method [25, 37-39], although few researchers correct inflammatory mediators such as eosinophil cationic protein, IgE and other Igs according to either albumin or urea concentrations [40, 41]. CCL1 levels were also calculated according to albumin concentrations in BALF. However, there was no statistical difference from that expressed per $\mathrm{mL}$ of BALF (data not shown). Interestingly, a European Respiratory Society Task Force report [42] concludes that results of acellular components should be expressed as amounts per $\mathrm{mL}$ in order to facilitate comparison of data from different works until a reliable external marker can be defined. Previous studies have detected other CD4-activating chemokines, including CCL17 and CCL22 in stable asthmatics $[18,37]$. The present authors therefore suggest that CCL1, in concert with other CD4activating chemokines, such as CCL22 and CCL17, may be involved in the recruitment of lymphocytes into the airways of asthmatic patients.

In order to further investigate CCL1, the gene encoding of this cytokine was studied. Increased CCL1 mRNA expression was seen in BAL cells from asthmatic patients compared with that observed in cells obtained from normal subjects. This finding further suggests that CCL1 is highly regulated in asthma.

Having unequivocally shown increased immunoreactive CCL1 and CCL1 gene upregulation, the present authors wondered whether biologically active CCL1 could be identified in BALF. The present authors have previously shown that BALF constitutes an excellent tool to study cell attractants [25, 27]. Indeed, separation of BALF by sequential CCL1 affinity chromatography and reverse phase-chromatography enabled the identification of a peak of LCA, which, by using ELISA, was found to correspond to CCL1. The biological activity associated with these fractions could be abolished completely using a neutralising antibody in CCL1. Thus, the finding that BAL CCL1 activates CD4 cells expressing CCR8 in vitro (fig. 4) together with the demonstration that CCL1 levels showed a trend towards a correlation with lymphocyte numbers in BALF suggest that when released locally, this cytokine may attract CD4 cells into the airways of asthmatics.

To investigate the cellular source of the CCL1 detected in BALF, an immunohistochemical staining of bronchial biopsies was performed. This allowed the present authors to demonstrate that CCL1 immunoreactivity was predominantly localised to the airway epithelium. Moreover, levels of CCL1 correlated with the number of airway epithelial cells in BALF and these cells correlated with lymphocytes. This suggests that during the inflammatory process airway epithelial cells may release CCL1 and this cytokine in turn may recruit lymphocytes into the airways of asthmatics. Interestingly, the number of airway epithelial cells in BALF from asthmatics was greater compared with that observed in BALF from control subjects and it is likely that they may have accounted for the increased CCL1 mRNA expression observed in BAL cells. Thus, it could be suggested that epithelial cells shed from the airways could be a major cell source of CCL1 in vivo. To further investigate CCL1 production, primary BAEC were stimulated with either Th1 or Th2 cytokines. Interestingly, IL-4 was found to be a strong stimulus for CCL1 release from BAEC, followed by IL-13 and IFN- $\gamma$. Both IL-4 and IL-13 are known to play an important role in allergic inflammation. These cytokines activate B-cells, inducing class switching to $\operatorname{IgE}$ and expression of both CD23 and class II major histocompatibility complex antigens $[43,44]$. Increased mRNA encoding IL-4 and IL-13 has been reported in both bronchial biopsies and BAL cells from asthmatics [45]. Taken together these observations suggest that IL-4, IL-13 and IFN- $\gamma$ may induce CCL1 release into asthmatic airways; however, further studies must investigate in more detail the production of this cytokine by BAEC.

To date, there are no in vivo studies showing the direct effect of CCL1 on normal airways. Thus, it is not known whether CCL1 induces bronchial hyperreactivity. The present study did not find a correlation between CCL1 levels and bronchial hyperreactivity (PC20 methacholine), which is not surprising. The present authors suggest that CCL1 induces recruitment of Th2 cells, which in turn may release cytokines such as IL-4, IL5 and IL-13. These cytokines are potent inductors of bronchial hyperreactivity. Thus, it is tempting to suggest that neutralising the effects of CCL1/CCR8 may have a substantial impact on allergic disease. Indeed, a previous study has shown that the use of an anti-CCL1 antibody inhibits the eosinophil recruitment into the lung of sensitised mice [20]. Similarly, CHENSUE et al. [21] demonstrated that CCR8-/- mice had impaired pulmonary eosinophilia although other authors have failed to reproduce these findings [22]. Interestingly, increased CCR8 immunoreactivity, localised to Th2 cells, has been previously found in bronchial biopsies derived from asthmatics and its expression correlated with bronchial hyperreactivity [18]. More recently, CCR8 has been reported to be expressed in both Th1 and Th2 skin lymphocytes [46]. The development of small CCL1 antagonists with clinical efficacy will define the role of this cytokine in asthma. However, future studies must also investigate the effect of corticosteroids, the mainstay treatment of asthma, on CCL1 release.

In summary, the present study has demonstrated that asthmatics release increased concentrations of CC chemokine ligand 1 in bronchoalveolar lavage fluid. The levels of this cytokine were found to be associated with an increased number of lymphocytes in bronchoalveolar lavage fluid. Bronchoalveolar lavage CC chemokine ligand 1-induced migration of CD4 cells expressing CC chemokine receptor 8 in a chemotactic assay. Using immunohistochemistry, CC chemokine ligand 1 immunoreactivity was localised predominantly to the bronchial airway epithelium. Interestingly, both CC chemokine ligand 1 levels and lymphocyte numbers correlated with airway epithelial cell numbers in bronchoalveolar lavage fluid. Moreover, bronchial airway epithelial cells were found to release $\mathrm{CC}$ chemokine ligand 1 in vitro. Taken together these findings suggest that $\mathrm{CC}$ chemokine ligand 1 may play a role in the recruitment of lymphocytes that characterise bronchial asthma. 


\section{ACKNOWLEDGEMENTS}

The authors are grateful to B. Dávila for recruiting some of the volunteers for the present study.

\section{REFERENCES}

1 Foster PS, Martinez-Moczygemba M, Huston DP, Corry DB. Interleukins-4 -5 and -13 : emerging therapeutic targets in allergic disease. Pharmacol Ther 2002; 94: 253-264.

2 Robinson DS, Hamid Q, Ying S, et al. Predominant TH2like bronchoalveolar T-lymphocyte population in atopic asthma. N Engl J Med 1992; 326: 298-304.

3 Bentley AM, Meng Q, Robinson DS, Hamid Q, Kay AB, Durham SR. Increases in activated T lymphocytes, eosinophils, and cytokine mRNA expression for interleukin-5 and granulocyte/macrophage colony-stimulating factor in bronchial biopsies after allergen inhalation challenge in atopic asthmatics. Am J Respir Cell Mol Biol 1993; 8: 35-42.

4 Del Prete GF, De Carli M, D'Elios MM, et al. Allergen exposure induces the activation of allergen-specific Th2 cells in the airway mucosa of patients with allergic respiratory disorders. Eur J Immunol 1993; 23: 1445-1449.

5 Bodey KJ, Semper AE, Redington AE, et al. Cytokine profiles of BAL T-cells and T-cell clones obtained from human asthmatic airways after local allergen challenge. Allergy 1999; 54: 1083-1093.

6 Zlotnik A, Yoshie O. Chemokines: a new classification system and their role in immunity. Immunity 2000; 12: 121-127.

7 Teran LM. CCL chemokines and asthma. Immunol Today 2000; 21: 235-242.

8 Miller MD, Hata S, De Waal Malefyt R, Krangel MS. A novel polypeptide secreted by activated human T lymphocytes. J Immunol 1989; 143: 2907-2916.

9 Miller MD, Krangel MS. The human cytokine I-309 is a monocyte chemoattractant. Proc Natl Acad Sci USA 1992; 89: 2950-2954.

10 D'Ambrosio D, Iellem A, Bonecchi R, et al. Selective upregulation of chemokine receptors CCR4 and CCR8 upon activation of polarized human type 2 Th cells. J Immunol 1998; 161: 5111-5115.

11 Zingoni A, Soto $\mathrm{H}$, Hedrick JA, et al. The chemokine receptor CCR8 is preferentially expressed in Th2 but not Th1 cells. I Immunol 1998; 161: 547-551.

12 Miller MD, Wilson SD, Dorf ME, Seuanez HN, O’Brien SJ, Krangel MS. Sequence and chromosomal location of the I309 gene. Relationship to genes encoding a family of inflammatory cytokines. J Immunol 1990; 145: 2737-2744.

13 Selvan RS, Zhou LJ, Krangel MS. Regulation of I-309 gene expression in human monocytes by endogenous interleukin-1. Eur J Immunol 1997; 27: 687-694.

14 Haque NS, Zhang X, French DL, et al. CC chemokine I-309 is the principal monocyte chemoattractant induced by apolipoprotein(a) in human vascular endothelial cells. Circulation 2000; 102: 786-792.

15 Roos RS, Loetscher M, Legler DF, Clark-Lewis I, Baggiolini M, Moser B. Identification of CCR8, the receptor for the human CC chemokine I-309. J Biol Chem 1997; 272: 17251-17254.

16 Tiffany HL, Lautens LL, Gao JL, et al. Identification of CCR8: a human monocyte and thymus receptor for the CC chemokine I-309. J Exp Med 1997; 186: 165-170.
17 Panina-Bordignon $\mathrm{P}$, Papi A, Mariani M, et al. The C-C chemokine receptors CCR4 and CCR8 identify airway $\mathrm{T}$ cells of allergen-challenged atopic asthmatics. J Clin Invest 2001; 107: 1357-1364.

18 Bochner BS, Hudson SA, Xiao HQ, Liu MC. Release of both CCR4-active and CXCR3-active chemokines during human allergic pulmonary late-phase reactions. J Allergy Clin Immunol 2003; 112: 930-934.

19 Lezcano-Meza D, Negrete-Garcia C, Dante-Escobedo M, Teran LM. The monocyte derived chemokine (MDC) is released into the bronchoalveolar lavage fluid of steady state asthmatics. Allergy 2003; 58: 1125-1130.

20 Bishop B, Lloyd CM. CC chemokine ligand 1 promotes recruitment of eosinophils but not Th2 cells during the development of allergic airway disease. J Immunol 2003; 170: 4810-4817.

21 Chensue SW, Lukacs NW, Yang TY, et al. Aberrant in vivo $\mathrm{T}$ helper type 2 cell response and impaired eosinophil recruitment in CC chemokine receptor 8 knockout mice. J Exp Med 2001; 193: 573-584.

22 Chung CD, Kuo F, Kumer J, et al. CCR8 is not essential for the development of inflammation in a mouse model of allergic airway disease. J Immunol 2003; 170: 581-587.

23 National Heart, Lung and Blood Institute. Workshop summary and guidelines: investigative use of bronchoscopy, lavage, and bronchial biopsies in asthma. J Allergy Clin Immunol 1991; 88: 808-814.

24 Harder J, Meyer-Hoffert U, Teran LM, et al. Mucoid pseudomonas aeruginosa, TNF-alpha, and IL-1 beta, but not IL-6, induce human beta-defensin-2 in respiratory epithelia. Am J Respir Cell Mol Biol 2000; 22: 714-721.

25 Teran LM, Noso N, Carroll M, Davies DE, Holgate ST, Schröder JM. Eosinophil recruitment following endobronchial allergen challenge is associated with the release of the chemokine RANTES into asthmatic airways. J Immunol 1996; 157: 1806-1812.

26 Colantonio L, Recalde H, Sinigaglia F, D'Ambrosio D. Modulation of chemokine receptor expression and chemotactic responsiveness during differentiation of human naive T cells into Th1 and Th2 cells. Eur J Immunol 2002; 32: 1264-1273.

27 Teran LM, Campos MG, Begishvilli BT, et al. Identification of neutrophil chemotactic factors in bronchoalveolar lavage fluid of asthmatic patients. Clin Exp Allergy 1997; 27: 396-405.

28 Synek M, Beasley R, Frew AJ, et al. Cellular infiltration of the airways in asthma of varying severity. Am J Respir Crit Care Med 1996; 154: 224-230.

29 Velazquez JR, Lacy P, Moqbel R. Replenishment of RANTES mRNA expression in activated eosinophils from atopic asthmatics. Immunology 2000; 99: 591-599.

30 Burd PR, Freeman GJ, Wilson SD, et al. Cloning and characterization of a novel $\mathrm{T}$ cell activation gene. J Immunol 1987; 139: 3126-3131.

31 Goya I, Gutierrez J, Varona R, Kremer L, Zaballos A, Marquez G. Identification of the CCR8 as the specific receptor for the human beta-chemokine I-309: cloning and molecular characterization of murine CCR8 as the receptor for TCA-3. J Immunol 1998; 160: 1975-1981.

32 Scheerens H, Hessel E, de Waal-Malefyt R, Leach MW, Rennick D. Characterization of the chemokines and 
chemokine receptors in two murine models of inflammatory bowel disease: IL-10-/-mice and Rag-2-/-mice reconstituted with CD4+CD45RBhigh T cells. Eur J Immunol 2001; 31: 1465-1474.

33 Teuscher C, Butterfield RJ, Ma RZ, Zachary JF, Doerge RW, Blankenhorn EP. Sequence polymorphism in the chemokines Scyal (TCA-3), Scya2 (monocyte chemoattractant protein (MCP)-1) and Scyal2 (MCP-5) are candidates for eae7, a locus controlling susceptibility to monophasic remitting/nonrelapsing experimental encephalomyelitis. J Immunol 1999; 163: 2262-2266.

34 Jones KP, Edwards JH, Reynolds SP, Peters TJ, Davies BH. A comparison of albumin and urea as reference markers in bronchoalveolar lavage fluid from patients with interstitial lung disease. Eur Respir J 1990; 3: 152-156.

35 Rennard SI, Basset G, Lecossier D, et al. Estimation of volume of epithlelial lining fluid recovered by lavage using urea as marker of dillution. J Appl Physiol 1986; 60: 532-538.

36 Marcy TW, Merrill WW, Rankin JA, Reynolds HY. Limitations of using urea to quantify epithelial lining fluid recovered by bronchoalveolar lavage. Am Rev Respir Dis 1987; 135: 1276-1280.

37 Lilly CM, Nakamura H, Belostotsky OI, et al. Eotaxin expression after segmental allergen challenge in subjects with atopic asthma. Am J Respir Crit Care Med 2001; 163: 1669-1675.

38 Lezcano Meza D, Negrete Garcia MC, Montes Vizuet A, et al. La quimiocina regulada y activada del timo (TARC) se libera en las vías aéreas de pacientes asmáticos. [The chemokine thymus- and activation-regulated chemokine (TARC) is released into the airways of asthmatic patients.] Rev Inst Nal Enf Resp Mex 2002; 115: 201-205.
39 Holgate ST, Bodey KS, Janezic A, Frew AJ, Kaplan AP, Teran LM. Release of RANTES, MIP-1 alpha and MCP-1 into asthmatic airways following endobronchial allergen challenge. Am J Respir Crit Care Med 1997; 156: 1377-1383.

40 Oddera S, Silvestri M, Galeazzi G, Crimi E, Rossi GA. Airway eosinophilic inflammation and bronchial hyperresponsiveness after allergen inhalation challenge in asthma. Lung 1998; 176: 237-247.

41 Wilson DR, Merrett TG, Varga EM, et al. Increases in allergen-specific IgE in BAL after segmental challenge in atopic asthmatics. Am J Respir Crit Care Med 2002; 165: 22-26.

42 Haslam PL, Baughman RP. Report of ERS Task Force: guidelines for measurement of acellular components and standardization of BAL. Eur Respir J 1999; 14: 245-248.

43 Ryan JJ. Interleukin-4 and its receptor: Essential mediators of the allergic response. J Allergy Clin Immunol 1997; 99: $1-5$.

44 Brombacher $\mathrm{F}$. The role of interleukin-13 in infectious diseases and allergy. Bioessays 2000; 22: 646-656.

45 Ying S, Durham SR, Corrigan CJ, Hamid Q, Kay AB. Phenotype of cells expressing mRNA for TH2-type (interleukin 4 and interleukin 5) and TH1-type (interleukin 2 and interferon gamma) cytokines in bronchoalveolar lavage and bronchial biopsies from atopic asthmatic and normal control subjects. Am J Respir Cell Mol Biol 1995; 12: 477-487.

46 Schaerli P, Ebert L, William K, et al. A skin-selective homing mechanism for human surveillance T cells. J Exp Med 2004; 199: 1265-1275. 